\title{
NATÚRAM Y ALMA EN LA GUERRA: EL PROCESO DE CONSTITUCIÓN DE LA CONCIENCIA DE UN GRUPO DE JÓVENES EXCOMBATIENTES EN COLOMBIA*
}

\author{
NATÚRAM AND SOUL IN WAR: THE PROCESS OF THE CREATION OF \\ CONSCIOUSNESS IN A GROUP OF YOUNG, FORMER COMBATANTS IN \\ COLOMBIA
}

Ricardo Andrés Delgado-Cardona**

\begin{abstract}
Resumen
Objetivo. Presentar parte de los resultados derivados del proceso de investigación sobre la constitución psicológica expresada en los sueños de jóvenes excombatientes en Colombia, desarrollado entre los años 2015-2016. El artículo expone la influencia de la relación con la naturaleza -natúram- en la constitución de la realidad psíquica de un grupo de jóvenes excombatientes. Metodología. Proceso de interpretación de hermenéutica dialéctica. Orientado a develar la lógica psíquica expresada a través de los sueños. Resultados. La constitución psicológica en los jóvenes excombatientes se encuentra influenciada y orientada por las formas en las que la conciencia se constituye a partir de su relación con la naturaleza. Conclusiones. Los procesos de diseño, implementación y ejecución de programas para la reintegración social y productiva han de considerar las formas en las que los jóvenes construyen y comprenden la realidad, como formas de fortalecer y facilitar los procesos de los jóvenes excombatientes.
\end{abstract}

Palabras clave: psicología, sueños, natura, excombatientes.

\begin{abstract}
Objective. To present part of the results derived from the research process on the psychological formation expressed in the dreams of young former combatants in Colombia (2015-2016). The article exposes the influence of the relationship with nature -natúram- in the formation of the psychic reality of a group of young former combatants. Methodology. Comprehension process of dialectical hermeneutics, oriented to unveil the psychic logic expressed through dreams. Results. The psychological formation of young former combatants is influenced and guided by the ways in which consciousness is formed based on its relation to nature. Conclusions. The process of design, implementation and execution of the social and productive reintegration programs should consider the ways in which young people construct and comprehend reality as a way of strengthening and facilitating the processes of young former combatants.
\end{abstract}

Key words: psychology, dreams, nature, ex-soldiers.

\footnotetext{
* El artículo es producto del proceso de investigación “Sueños, alma y guerra: un estudio psico-lógico sobre la expresión del alma en los sueños de jóvenes excombatientes en Colombia”, desarrollada durante el año 2016 en el marco del proceso de Maestría en Ciencias Sociales de la Universidad de Caldas, desarrollado por el autor.

*** Universidad de Caldas. Manizales, Colombia. E-mail: ricardo.delgado@ucaldas.edu.co -

(D) orcid.org/0000-0002-7821-926X Google Scholar
}

rev. eleuthera. 19, julio-diciembre 2018, 37-54 


\section{Introducción}

Este artículo corresponde a la presentación de uno de los apartes de los resultados obtenidos dentro de la investigación "Sueños, alma y guerra: un estudio psicológico' sobre la expresión del alma en los sueños de jóvenes excombatientes en Colombia”, desarrollada durante los años 2016-2017. Específicamente, el artículo presenta los apartes correspondientes a la influencia de experiencias y lógicas propias de ámbitos naturales como el campo o la selva en la constitución de la consciencia de un grupo de jóvenes excombatientes.

Esta investigación se desarrolló adoptando una perspectiva teórica novedosa con respecto a la psicología tradicional, una propuesta que entiende a la psicología como el estudio del alma y a esta como un proceso lógico a partir del cual se construye la realidad y se vivencian las diferentes experiencias y fenómenos. Lo anterior puede expresarse de la siguiente manera: “El alma es en el fondo vida lógica o idea" (Giegerich, 1998, p. 1). Esta visión corresponde a una de las líneas de desarrollo de la psicología analítica o “junguiana”, la cual es considerada como el tercer momento de despliegue de este pensamiento, cuyo principal exponente es Wolfgang Giegerich y, asimismo, ha sido denominada como psicología de la interioridad.

Es importante considerar para el contexto teórico del artículo que, a partir del trabajo de Carl Gustav Jung se derivan tres momentos u olas del pensamiento junguiano: 1) La psicología analítica de Jung como marco general de la teoría junguiana. 2) La psicología arquetipal de James Hillman, caracterizada por la propuesta de superar la tendencia a la hipóstasis -propia del junguianismo tradicional-y enfatizar en el entendimiento de la psique como un hacer a través de la imaginación. 3) La psicología de la interioridad o lógica de Wolfgang Giegerich, que incorpora a la psicología de Hillman la idea de que el alma es tanto imagen como pensamiento, y se entiende a esta como forma de conciencia, proceso, vida lógica generadora de sí misma a través de la cual experimentamos y vivimos la realidad.

La psicología no trata de la vida ni de los fenómenos de la vida, no trata de la gente y de su desarrollo o conducta, sino que versa sobre "el alma", la "vida lógica", la dialéctica operativa dentro de tales fenómenos de la vida, dentro de las conductas de la gente. (Giegerich, 2005, p. 1)

En este sentido, este estudio entiende la guerra y los sueños como expresiones del alma, al igual que cualquier otra forma de experiencia, por lo que los sueños de los jóvenes excombatientes se tendrán en cuenta para acceder y amplificar la comprensión psico-lógica del alma encarnada en ellos. En este caso, se ha optado por la elección de un ámbito como son los sueños que,

\footnotetext{
${ }^{1}$ Durante el artículo se encontrará escrita la palabra 'psicología' y otros términos derivados del siguiente modo: psico-logía. Se adopta el uso del término de la psicología dialéctica y se denota el énfasis sobre el entendimiento de lo psico-lógico, como el estudio de la lógica del alma (psique).
} 
aunque resulta común y cotidiano, es al mismo tiempo un campo poco aprovechado dentro de los estudios psicológicos y sociales.

En síntesis, este estudio persigue el interés comprensivo de la vida lógica implicada en la experiencia onírica de un grupo de jóvenes excombatientes de fuerzas armadas ilegales, que vivieron tempranamente en su infancia y adolescencia el reclutamiento militar por parte de estos grupos armados y, con posterioridad, el paso por las experiencias de desmovilización y reintegración a la vida civil.

El artículo se compone de las siguientes partes: la primera parte presenta aspectos generales sobre el conflicto armado y reclutamiento de niños, niñas y jóvenes en Colombia. La segunda parte plantea los elementos fundamentales de la perspectiva psicológica adoptada en relación al sueño. La tercera parte despliega las implicaciones de la dimensión natura en la constitución psico-lógica y, la cuarta parte, refiere la importancia de la constitución de la conciencia en relación a los procesos de desmovilización armada e incorporación social de los que hacen parte los niños, niñas y jóvenes excombatientes.

\section{Metodología}

Este artículo es derivado de un proceso de investigación cualitativo de tipo hermenéutico, desarrollado a partir de los presupuestos de la hermenéutica dialéctica hegeliana, lo que implica como procedimiento de análisis el sometimiento del objeto de estudio al proceso derivado de los cuatro momentos del proceso dialéctico hegeliano: afirmación, negación de la afirmación, negación de la negación y afirmación sublada -superación-. Con el propósito de develar y comprender la sintaxis constitutiva o lógica del alma expresada a través los sueños de los jóvenes excombatientes.

Para ampliar la concepción de la dialéctica hegeliana que soporta el proceso interpretativo puede seguirse lo resumido por Ellacuría (como se citó en Jaramillo, 1986), quien al respecto plantea:

para Hegel, la negación es una fuerza creativa, la negación crea su opuesto. La negación, en lugar de ser principio de división, es principio de unidad, aunque de unidad superada y dialéctica, porque en la unidad del todo en movimiento se da la identidad de la identidad y de la noidentidad. La identidad resultante es una identidad superior que engloba lo que cada cosa tiene a la vez de sí misma y no de sí misma: cada cosa es lo que es presente e inmediatamente, pero al mismo tiempo es realmente lo que todavía no es y pugna por ser frente a lo que ya está siendo como "momento" de una totalidad procesual, "momento" que debe dejar de ser para que el todo se realice procesualmente, pero que 
su dejar de ser no es mero pasar, sino un ser sobrepasado por la negación activa de lo que va a llegar a ser (...); los dos momentos contradictorios dan paso a una unidad superior que deja atrás la unidad hasta entonces lograda, reasumiendo los momentos contrarios en una unidad nueva, en la que se dan abolidos pero al mismo tiempo conservados. No hay momento quieto o etapa final. La negación -como momento creadordebe ser también negada, e incluso la unidad superior nueva contiene de forma distinta una nueva contradicción, que es la continuación en otra forma de aquella misma que ya ha sido superada pero al mismo tiempo ha sido conservada, aunque cualitativamente transformada. (p. 30)

En correspondencia con lo planteado, se entiende como pretensión acceder a la verdad psicológica, sintaxis constitutiva o lógica del alma de los sueños a través del proceso de develamiento derivado del proceso dialéctico.
El reino de la imaginación, no es un puro caos dominado por el azar y la arbitrariedad. Sino más bien un cosmos dotado de su propia articulación interna. En efecto, el estudio comparativo descubre a través de la inmensa pluralidad de símbolos que pueblan el universo del discurso humano ciertas convergencias y correspondencias que permiten agruparlos en diferentes constelaciones o camadas. (Garagalza, 1990, p. 118)

El proceso de análisis de los sueños de los jóvenes se desarrolla de la siguiente manera:

Primer momento de afirmación, correspondiente a la definición del objeto de estudio que para el caso corresponde a los sueños de los jóvenes excombatientes, en su condición subjetiva, literal y sin interpretación. El proceso de registro se realizó de forma individual a través protocolos orientadores que implicaban una descripción literal del sueño en audio y su posterior transcripción. El proceso se llevó a cabo durante varios meses, en períodos disímiles que van desde uno hasta 10 meses - dependiendo del proceso y de las particularidades de cada caso- .

Segundo momento, negación o momento de intersubjetividad y semántica que corresponde al proceso de negación y superación de la condición material, literal y subjetiva de los sueños registrados y presentados en el apartado anterior. Este proceso conlleva al abordaje de los sueños en su dimensión negativa privilegiando sus contenidos, temas y elementos comunes entre los diferentes participantes. Lo anterior implicó un juicio de expertos, el uso de la herramienta estadística de ponderación para superar la disparidad de los registros y la categorización e integración de los registros a partir de recurrencias semánticas. 
La subjetividad, tal como viera Husserl, se revela últimamente como intersubjetividad $y$, en consecuencia, al profundizar en la propia subjetividad se puede llegar a tocar las matrices de la intersubjetividad puesto que, al fin y al cabo, todos compartimos la misma naturaleza humana, el mismo inconsciente colectivo. (Garagalza, 1990, p. 119)

Tercer momento, negación de la negación. Este momento implica ir más allá de los aspectos semánticos, de los temas comunes y con ello de la condición de intersubjetividad de los sueños, de este modo ya no son sueños literalizados ni tematizados sino sueños lógicos. Emergen las categorías constitutivas de los temas, la sintaxis del fenómeno que para el caso del artículo corresponde a la expresión de natúram como orden constitutivo de las experiencias oníricas.

Cuarto momento, afirmación sublada, superación o momento afirmativo, el cual corresponde al despliegue interpretativo derivado de la emergencia de los elementos constitutivos del sueño, es decir a las interpretaciones emergentes, las nuevas afirmaciones -subladas-o nuevas comprensiones de la experiencia onírica como la que se expone en este artículo con respecto al papel de natúram en la constitución psico-lógica de los sueños abordados.

\section{Resultados}

\section{Generalidades del conflicto armado en Colombia y el reclutamiento de niños, niñas y jóvenes}

La historia de Colombia ha estado ligada a la guerra. Por lo que, desde su constitución como Nación hasta los días contemporáneos, es posible rastrear diferentes versiones del conflicto armado derivadas de factores sociopolíticos.

Colombia se encuentra en los primeros lugares de desigualdad, concentración de la riqueza y propiedad en el mundo. Esta situación, expresada en diferentes conflictos sociales tales como la alta cantidad de tierras en manos de unos pocos, la exclusión social y la baja efectividad del Estado para el trámite y la regulación de estas tensiones, ha servido de origen, insumo, cultivo y sostenimiento de confrontaciones armadas, así como de la naturalización de la violencia armada y de sus prácticas en la vida social.

Hoy en día, y desde hace cerca de 50 años, se vive la última versión de estas confrontaciones. Un conflicto que reúne a actores armados como los grupos contraestatales guerrilleros (FARC-EP, ELN y EPL, al igual que otros grupos de menor presencia o que han desaparecido o mutado entre los antes mencionados), los actores de acción paraestatal o paramilitares (grupos de autodefensas de terratenientes y narcotraficantes derivados de organismos del Estado, cuya última mutación son las bandas criminales o BACRIM) y los agentes del Estado (Policía y Ejército Nacional). 
A esta incapacidad del Estado colombiano de ejercer sus funciones y de crear las garantías necesarias para la inclusión, la protección social y la aplicación de la justicia, así como la naturalización de las violencias, las formas y las prácticas asociadas a la vida armada, se suman factores de desigualdad, exclusión y pobreza que son generadores en su conjunto de las condiciones propicias de vulnerabilidad para que miles de niños, niñas y jóvenes en Colombia sean víctimas del flagelo de la guerra, en especial del desplazamiento forzado, las minas antipersona, el tráfico sexual, la explotación laboral, y una cruel versión de este último: el reclutamiento forzado.

Algunos de los puntos críticos a considerar sobre las problemáticas anteriormente mencionadas son las dificultades para conocer de forma precisa el número de niños, niñas y jóvenes afectados. En este caso, se propone considerar las cifras presentadas por Springer (2012) en el informe Como corderos entre lobos, acerca del uso y reclutamiento de niñas, niños y adolescentes en el marco del conflicto armado y la criminalidad en Colombia como los datos de referencia.

En cifras, los resultados del modelo dinámico nos permiten inferir que no menos de 18.000 niños, niñas y adolescentes forman parte de grupos armados ilegales y organizaciones criminales y no menos de 100.000 están vinculados a sectores de la economía ilegal directamente controlada por grupos armados ilegales y organizaciones criminales. (Springer, 2012, p. 30)

\section{Alma y sueño}

Para clarificar la perspectiva teórica asumida en este trabajo se requiere exponer dos ideas de forma puntual: 1) este trabajo entiende por alma ${ }^{2}$ al original y desatendido objeto de estudio de la psicología, a saber: el movimiento lógico del proceso de la consciencia o psico-lógico, y 2) se asumen los sueños o experiencias oníricas como objeto de estudio y como expresiones de la vida lógica. A continuación se desarrollan los anteriores planteamientos y su relación con la experiencia de jóvenes excombatientes.

El alma es un proceso, un movimiento lógico, una perspectiva, una referencia o una mirada de los procesos psíquicos implicados en el entendimiento. Por tanto, en la forma como se construye la realidad psíquica es el cómo de la consciencia, es una cualidad; su uso es ante todo como un adjetivo antes que un sustantivo. Mientras que la psicología (psico-psique, logí-logos) es el proceso a través del cual se hace logos del alma, lo psíquico así se convierte en verdad psicológica.

\footnotetext{
${ }^{2}$ El concepto 'alma' considerado en este documento ha de entenderse en su equivalente a proceso lógico de la consciencia, es fundamentalmente proceso de imagen y pensamiento en la perspectiva de la psicología analítica; lo que ha de ser diferenciado del uso del término en otros ámbitos para referirse a entes o substancias.
} 


\begin{abstract}
No estamos proponiendo u ontologizando al alma como una hipóstasis (...) No la concebimos como un objeto, como una cosa, un ser natural o una esencia, una sustancia metafísica, una entidad, "el fantasma en la máquina”. No está construida por nosotros como un sujeto ni como un agente o director invisible detrás del escenario. Ni tampoco es vista como un componente o como un compartimento del hombre y como teniendo un sustrato. (Giegerich, 2012, p. 23)
\end{abstract}

Pensar el alma como vida lógica, como constitución de la consciencia, implica entender que son amplias y diversas sus formas de expresión y sus vías de acceso. En este caso, en el que se pretende conocer su expresión, se ha elegido la vía onírica, a partir de los sueños de los participantes del estudio aunados a un grupo de sueños retomados de investigaciones desarrolladas en períodos de tiempo semejantes y con población de similares características.

Los sueños de los jóvenes excombatientes son asumidos como la expresión del mundo psicológico a develar. Se pretende que sea el alma la que a través del ámbito onírico devele su constitución antes que centrar los desarrollos y esfuerzos comprensivos en la expresión del ego individual o colectivo de los soñantes.

Se asume esta perspectiva con la intención de permitir el entendimiento del fenómeno psico-lógico, que se expresa por medio de manifestaciones oníricas. Es decir, a diferencia del tendiente subjetivismo imperante en la psicología tradicional, este estudio involucra -pero de igual modo supera- las características particulares y personales del sujeto; incluso, lo hace con los elementos comunes e intersubjetivos entre los soñantes para dar paso prioritario a una forma de abordaje centrado en la sintaxis y en el movimiento lógico de la consciencia instaurada en los sueños.

Lo anterior implica entender que el sueño no es una experiencia homogénea, ajena al tiempo y a la cultura, y no puede serlo porque es una experiencia y una expresión ineludible de la constitución de la consciencia en un momento específico. El sueño se experimenta y comprende a través de los alcances y límites ofrecidos por la vida lógica en un momento dado, en otras palabras: se sueña en los horizontes y fronteras que posibilita el alma.

El sueño no es únicamente un fenómeno espontáneo y privado de la mente, forma también parte de una experiencia más vasta de la historia cultural humana. Por muy fantasmales o arbitrarias que nos parezcan estas tácitas vivencias nocturnas, algunas de ellas poseen una historicidad concreta, una cualidad particular que las hace pertenecer con todo derecho a la memoria histórica. (Jung, 1995, p. 14) 
Natúram y alma en la guerra: el proceso de constitución de la conciencia de un grupo de jóvenes excombatientes en Colombia

Asumir la perspectiva de la lógica del alma para entender sus manifestaciones oníricas -las del alma-, en los sueños de un grupo de jóvenes excombatientes, representa la posibilidad de contribuir al conocimiento de las imágenes y al pensamiento que soporta el entendimiento de sus experiencias, así como avanzar en la comprensión de las imágenes y del pensamiento del alma - vida lógica- que se manifiestan a través de la guerra y sus derivados, tal como puede ser el reclutamiento.

Es también, la posibilidad de gestar vida psicológica en medio del automatismo inconsciente de la guerra, es la posibilidad de contribuir al hacer alma y consciencia psicológica sobre esta. Favoreciendo la transformación psicológica de las lógicas que le soportan y le mantienen. Poder comprender el mundo psico-lógico, la constitución de la consciencia, en el que habitan los jóvenes, lo cual les permite el ser en el mundo, es poder acceder a nuevas formas de amplificar las visiones de mundo e integrar aquellas que resultan ajenas a las suyas.

\section{Natúram, ruralidad y selva}

El término 'natúram' es utilizado normalmente en alusión a aquello que pertenece o se relaciona con el orden natural o las leyes de la naturaleza. En este caso, se asume como denominación psicológica que hace alusión al ordenamiento lógico de la conciencia implicada en los sueños y que se constituye a partir de las experiencias y referencias derivadas del orden natural y biológico.

Antes de continuar, resulta importante ampliar y precisar en qué términos y límites este estudio se refiere a la dimensión natúram. Para comenzar, natúram se entiende como una condición regida por la indiferenciación con el impulso y las leyes biológicas, entendiendo que "en la naturaleza no hay principio ni final, así como tampoco hay ahora, sino sólo un flujo continuo indiferenciado de acontecimientos... Estar envuelto en el orden natural de las cosas (incluyendo sus propios impulsos, emociones)" (Giegerich, 2008, p. 5).

Como es evidente, el hecho de pensar y exponer elementos reflexivos y comprensivos sobre natúram lleva implícita la superación del estado natural, la ocurrencia previa de su negación y sublación lógica; una diferenciación y una ruptura con la continuidad del instinto, con el animal, con la ley natural, y que ya ha acontecido para posibilitar la consciencia, el reflexionar y el discernir sobre el estado natural. Recordemos que "lo natural es inerte en un sentido análogo a la ley física de la inercia: su movimiento continúa sin cambios mientras no hayan otras fuerzas que se le interpongan" (Giegerich, 2008, p. 6).

Así, se plantea el concepto natúram debido a la relevancia en la constitución psicológica. Sin embargo, no se afirma que los soñantes, los sueños o la sintaxis de estos, se encuentren imbuidos en esta condición, ya que sería una contradicción. En cambio, se plantea a natúram como un elemento significativo en la constitución de la consciencia expresada como sueño. 
Algunos de estos elementos referidos aluden de manera reiterada, por ejemplo: a animales, vegetación, elementos naturales como el agua y también a la constitución de ambientes relacionados con la naturaleza como son el campo o la selva. Lo que sugiere la relevancia no solo semántica sino también sintáctica.

Las recurrencias de natúram en los sueños, el valor preponderante de esta condición en las dinámicas y en los contenidos oníricos, son una muestra del carácter determinante en el orden y la dinámica del sueño de los jóvenes excombatientes.

En primer lugar es importante considerar que la totalidad de los participantes del estudio provienen de ambientes rurales, caracterizados por hacer parte de las zonas más apartadas tanto geográfica como políticamente del país, pues son zonas donde los procesos tanto de urbanización como de modernización han estado profundamente limitados, lo que ha facilitado formas de vida cercanas al orden natúram debido a que muchos de los ambientes, problemas cotidianos y elementos están relacionados con sus órdenes, demandas y características naturales.

El ingreso de estos jóvenes a los grupos armados no es un punto de quiebre en la proximidad con natúram sino que, por el contrario, simboliza un mayor adentramiento en ella tanto en su sentido positivo y concreto como lógico. Por una parte, los hechos concretos representan una disminución en la relación con el campo y sus tareas y, por otra, un aumento en la vivencia directa del orden natural que impone la selva. Las tareas diarias del campo tales como el cultivo, la labor con los animales domésticos y los oficios cotidianos, son reemplazadas por la relación con la manigua, los animales salvajes y las leyes naturales que allí operan dadas las exigencias de sobrevivir tanto a las hostilidades de la guerra como a la dureza del mundo salvaje.

En este orden de ideas, las experiencias del campo y de la selva implican órdenes, ambientes, demandas y dinámicas propias del orden natúram. Estos son los elementos y las condiciones a partir de las cuales se posibilita, inicialmente, la constitución lógica de la consciencia que se expresa en los sueños.

Se puede encontrar la influencia constitutiva del orden lógico de natúram en dos coordenadas fundamentales para la conciencia, estas son: el tiempo y el espacio. En cuanto a la primera se pueden observar procesos asociados a los ciclos de eventos naturales, de producción agrícola o de pesca, y a las consideraciones del tiempo en relación con el presente inmediato; aparentemente asociado con una temporalidad centrada en la inmediatez del oficio del día a día, del acto de sobrevivencia cotidiano, que conlleva el afrontar los retos de una ruralidad abrupta y exigente.

Por tal motivo, se han de tener en cuenta las lógicas temporales que se dan en medio de la vida armada, las cuales están enmarcadas en una temporalidad inmediata atravesada por la sobrevivencia del momento a momento y en su forma extendida al día a día. 
Lo anterior se aprecia en el siguiente testimonio de una joven excombatiente al referirse a su vivencia en el grupo armado en el documental "Mi última marcha":

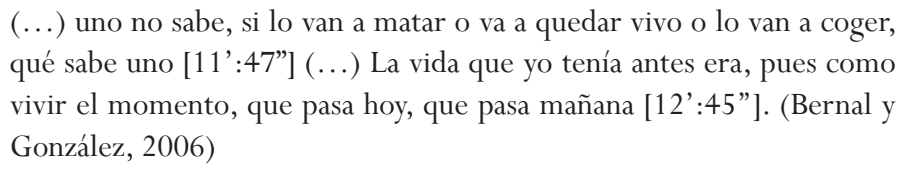

Hay que considerar que las referencias oníricas en las cuales se identifica a natúram como parte importante de su constitución lógica son sueños de reciente producción, aproximadamente de un con respecto de construcción del artículo; mientras que las experiencias de relación con natúram en lo que respecta al entorno rural tienen en promedio la ocurrencia entre 10 y 21 años (promedio de diferencias entre la fecha de nacimiento y la fecha de reclutamiento, respectivamente) y siete años con respecto al entorno de la selva (calculado a partir del promedio de permanencia en el grupo armado). Así que las últimas experiencias continuas de vivencia directa en relación a natúram tienen como mínimo siete años de diferencia entre su acontecer y la vivencia de los sueños registrados.

Esto supone dos asuntos importantes: el primero se refiere a la consideración del sueño como fenómeno residual de la experiencia diurna, lo que podría descartarse considerando la distancia temporal entre la experiencia directa y la onírica; mientras que el segundo se refiere a la necesidad de considerar la diferencia entre la temporalidad cronológica que obedece al orden de los hechos en correspondencia a esta y el tiempo lógico de la consciencia que se encuentra vinculado a los procesos dialécticos a través de los cuales se desenvuelve la constitución de la consciencia.

La historia, en este sentido, es ciertamente no el curso del tiempo -sin tomar en cuenta si se mira este curso como fluyendo desde el pasado hacia el presente y hasta el futuro- o si se imagina, opuestamente, que un futuro siempre nuevo se va transformando en el presente y luego más y más desaparece en el pasado distante. No, en contraste con este sentido de la historia de continuidad sin rupturas, la historia, en el sentido que necesita ser pensada aquí, es la continua generación y profundización, a partir de aquel origen, de una separación o de un distanciamiento. Es la apertura de una separación y una brecha cada vez mayor entre el significado por allí y la emancipación del significado aquí [el proceso dialéctico ${ }^{3}$. (Giegerich, 2006, p. 3)

\footnotetext{
${ }^{3}$ Esta referencia al "proceso dialéctico" no corresponde al texto original, es introducida con el fin de clarificar el planteamiento del tiempo de la consciencia anteriormente expuesto.
} 
Las implicaciones del tiempo dialéctico o lógico pueden advertirse, por ejemplo, a través del valor que le otorgan los jóvenes al momento presente, al momento inmediato, lo que conlleva a la concretud en las acciones; en contravía a los procesos que implican la espera, la mediación y la proyección en el tiempo, característicos de los órdenes temporales modernos e indispensables en la vida urbana. Considérese este como un aspecto transversal e indispensable en las propuestas de reintegración social y productiva donde la proyección de vida se constituye como meta y fundamento de base de las propuestas psicosociales.

Por su parte, la segunda coordenada, la del espacio, hace referencia a la relevancia y al ordenamiento espacial derivado de la relación estrecha con escenarios y ambientes naturales. Los sueños en este caso presentan de forma constante la alusión a escenarios tales como fincas, potreros, monte o selva donde los animales y la vegetación tienen relevancia y protagonismo. Al mismo tiempo son constantes las manifestaciones de anhelo y necesidad de estos escenarios por parte de los jóvenes.

Esta situación sugiere que el alma se encuentra no solo constituida, sino también habitando en natúram (es más que un referente fundante, es un presente lógico). Natúram impone su propio tiempo-espacio, traducido y expresado a través de la mediación de los jóvenes y su experiencia. Así, aunque cronológica y espacialmente estén en la ciudad, el alma mantiene como ámbito el orden de natúram.

Los guerrilleros salieron caminando del campamento hasta encontrar un camino de vereda. Allí esperaron hasta que pasó un jeep Willys, el primer carro que conoció Mariana. Ella recuerda como si las luces del carro fueran los ojos, es decir como si fuera un ser vivo y en movimiento. (Lugo, 2014, p. 201)

Vi una buseta grande, otros carros más chiquitos y yo aterrada y cómo cuando manejan carro eso funciona... yo miraba pa' bajo [sic] y me preguntaba ¿dónde tiene las patas y todo que camina?Y eran esas ruedas y yo miraba todo entretenidamente. (Lugo, 2014, p. 201)

Al otro día, salió a la calle, intentó subirse a un bus, pero le daba miedo, parecía que el bus se la quería tragar: "no, esta (la buseta) me tragó y yo me voy a quedar encerrada”. Sentía miedo de las puertas que se cerraban automáticamente, no entendía cómo podía suceder esto, similar a lo que ocurría con el carro que se movía solo. ¿Qué significará ver otro mundo por primera vez a los 15 años? Lo primero que la impresiona son las cosas: el carro, el bus, la casa, la cama. El mundo no es la selva, existe otro mundo, un mundo material. Un mundo mecánico y autónomo. Un mundo en movimiento. (Lugo, 2014, p. 201) 
Natúram y alma en la guerra: el proceso de constitución de la conciencia de un grupo de jóvenes excombatientes en Colombia

Otra forma de identificar la relevancia del natúram en el orden constitutivo de la conciencia puede ser a través de las metáforas y analogías construidas para ordenar las experiencias de vida de los jóvenes en el antes, durante la experiencia armada y en el después de la misma. Algunos ejemplos de ello refieren por ejemplo situaciones en las que se piensa la ciudad como un gran hormiguero, las tractomulas como madres de automóviles más pequeños, los aviones como aves, entre otros.

Al respecto, resulta orientador revisar apartes y planteamientos de otras experiencias de investigación, que si bien desarrollan el análisis en direcciones diferentes a las de este artículo y bajo otras perspectivas, también ilustran la relevancia de estas relaciones en la constitución de las lógicas planteadas.

Los animales no solamente fueron los compañeros de Mariana, sus juguetes, su protección, su alimento en circunstancias tan difíciles, el enlace afectivo con su padre, sino que también sirvieron para que el comandante le explicara a la niña, lo que no podía explicarle, escondieron verdades que no se atrevía a decirle... El comandante le decía en la selva que los helicópteros que se veían desde allá, punticos negros en el cielo, eran gallinazos y cuando ella conoció un gallinazo y descubrió la mentira, el comandante dijo que eran tiburones, un animal que ella nunca podría descubrir cómo era. Más tarde, ella se subiría a un gallinazo y el mito que había construido el padre, cobraría todo el sentido en su vida. (Lugo, 2014, p. 182)

Y por la noche él me decía: “¿qué soñó?, cuente”. "Soñé subiéndome a un gallinazo, soñé subiéndome a un carro - como se dice-..., soñaba con una bata rayada... -ahora que me doy cuenta de los uniformes-, con un cuaderno, un lápiz”. (Lugo, 2014, p. 182)

En relación a los datos obtenidos, resulta llamativo que de la totalidad de sueños abordados se identifique la presencia con elementos asociados al campo en un $51 \%$; además, que los elementos asociados a esta condición son incluso superiores en la ponderación (61\%). Es evidente que, pese al transcurrir del tiempo de los hechos, el presente psicológico se sigue desenvolviendo en correspondencia a elementos constitutivos de la consciencia asociados a natúram. Estos siguen siendo elementos de gran influencia espacio-temporal para la consciencia que se expresa en los contenidos oníricos.

A manera de ilustración de lo expuesto, se refieren a continuación breves apartados de sueños registrados para este estudio: 
Soñé que yo estaba con un poco de muchachos del programa, dentro de esos "X", y estábamos dentro de una selva y dentro de esa selva había animales, había potreros cuando en ese momento... (Joven A, comunicación personal, 14 de agosto de 2015)

Soñé que me encontraba con unos amigos en la finca, nos encontrábamos barequeando. (Joven C, comunicación personal, 26 de abril de 2015)

El sueño fue que iba por un camino, pero era el campo y tenía que llegar a una casa, pero entonces resulta que yendo para la casa tenía que bajar por una cañada. (Joven G, comunicación personal, 3 de junio de 2015)

Recuerdo una finca de mucha paz, árboles muy grandes y todo verde, escucho el sonido de los árboles con el viento, los pájaros silban. (Joven J, comunicación personal, 2 de diciembre de 2015)

Asimismo, es posible citar una serie de referentes del grupo de sueños en articulación con sueños de otras investigaciones: "Yo estaba en el monte, caminando. Me fijaba bien en las huellas, para saber por dónde meterme y que no me fueran a coger” (Aguirre, 2010, p. 107); “en algunos sueños estaba como en un potrero, caminaba” (Cifuentes, 2012, p. 182).

En tal sentido, se puede prever que aestos asuntos que permiten el desenvolvimiento, la ubicación y la actuación en el mundo, están orientados lógicamente por estos elementos constitutivos de la espacialidad. Vale la pena mencionar las habilidades expuestas por parte de los jóvenes para ubicarse y desplazarse en espacios amplios, a partir de referencias al ambiente que a la vez son asimiladas y acomodadas (en el sentido de Jean Piaget y en relación al proceso adaptativo) a nuevos ámbitos. Así que las mismas lógicas de ubicación, utilizadas en ambientes rurales que recurren a elementos naturales significativos (el árbol particular, la zona vegetal destacada, el río), son reemplazadas por elementos de peso que se destacan en ambientes urbanos. De este modo, es común encontrar que la consciencia se desenvuelve con impresionante complejidad y precisión para ubicarse, aquí la imagen y la representación se convierten en un elemento primordial en la mediación con el mundo mientras que aquellos procesos que involucran el manejo de elementos como dirección, instrucciones o rutas son aparentemente secundarios.

Esta situación puede ser comparada, con las debidas distancias, con la diferencia identificada entre la orientación espacial de la cultura egipcia y la cultura griega en la Edad Antigua. Los estudiosos de este campo han expuesto que mientras que el espacio para los egipcios era concreto y encarnado en los objetos, en el caso de los griegos se advertía un espacio concebido conceptualmente que posibilitaría el uso de la geometría. 


\begin{abstract}
Los egipcios consideraban la geometría como una cuestión de campos concretos rectangulares o triangulares. Los griegos la abstraen del plano de lo concreto y material y empiezan a pensar en rectángulos y triángulos puros (...). En geometría, no ya triángulos, sino la naturaleza de la triangularidad y las consecuencias que lógica y necesariamente se derivan de ser un triángulo. (Guthrie, 1984, p. 46)
\end{abstract}

Otro elemento que es importante mencionar, y con una aparente relación a la aptitud para el desenvolvimiento en el espacio, es la constante constitución de los sueños en escenarios abiertos (ponderado general del 79\%) y que involucran una invariable interacción y desenvolvimiento con el entorno onírico.

La naturaleza ofrece una condición aparentemente paradojal en tal sentido, un orden fijo y ordenado por las leyes del mundo natural y a la vez altamente aleatorio y cambiante; por lo menos, ante los ojos del observador moderno y urbano. Esta lógica, que ante los ojos del citadino moderno pareciera carecer de recursos para el afrontamiento del mundo, es en realidad un complejo y eficiente sistema de comprensión, orientación y acción frente a las demandas de natúram.

Es una lógica que sin ser plenamente equiparable a esta, como acto lógico que ya se ha instaurado a partir de una separación con ella, sí ha heredado y desplegado mecanismos eficaces y correspondientes tales como la orientación concreta, la respuesta inmediata, la fuerza y el impulso vital que permiten una actuación ajustada a los retos que se plantean.

Considerando las diferencias y distancias entre una lógica que conserva, aprovecha y despliega sus mecanismos a través de natúram y la condición de natural como tal, resultan oportunas las palabras de Giegerich (2004) con respecto a la eficiencia de los mecanismos naturales manifiestos en el animal, para este caso la efectividad: "El animal es muy realista, racional y sobrio; como dijo Jung (1930a), es un ciudadano de la naturaleza de buena conducta y respetuoso con las leyes (...). Su forma de vivir la vida es completamente profesional” (Giegerich, 2004, p. 7).

Lo que se pretende sustentar aquí no es una equiparación de la dinámica del orden natural y la lógica, expresada a través de los sueños de los jóvenes de este estudio, sino que los sueños analizados reflejan la constitución de la sintaxis lógica en su proximidad a natúram. La cual da cuenta de una lógica compleja y eficiente frente a las demandas del mundo y de los ambientes propios de natúram. Pero que igualmente es limitada frente a los retos de ambientes modernos y urbanos, al tiempo que es desconocida, incomprendida, inadvertida y observada bajo el sesgo de la lógica moderna que pretende medirla por medio de sus propias características. 
Una lectura de la lógica en relación a natúram o de sus expresiones, entendidas estas como formas de comprender, actuar o relacionarse individual o colectivamente por parte de los jóvenes desde una visión moderna como referente de medida, no solo resulta sesgada, restringida e incapaz de autorreflexión, sino también inconveniente para los propósitos racionales que la direccionan.

Estos sesgos se expresan en algunas comprensiones de investigaciones, diagnósticos o valoraciones de los programas del Estado, así como en los diseños de programas y proyectos institucionales; al igual que en las mismas disposiciones de grupos sociales frente a los jóvenes por el afán de implantar las racionalidades propias, las que a su entender son las más adecuadas, efectivas y convenientes. Prueba de lo anterior es el diseño de programas para la inserción social y productiva ubicados en las principales ciudades de Colombia, bajo las dinámicas urbanas y las racionalidades productivas con enfoques y apuestas que desconocen las características, la constitución, los recursos y las restricciones de una forma de pensamiento como la anteriormente expuesta.

Una situación como esta deriva en una tensión vivida no como autocontradicción dialéctica, sino como conflicto; autocontradicción, experimentada como el choque externo entre dos visiones de mundo; un conflicto aparente entre la perspectiva rural y urbana. Por tanto, se requiere de una amplitud lógica que vía negación supere este obstáculo y permita el reconocimiento y la superación-como sublación- de la condición en cuestión.

Esta situación se ve reflejada de manera reiterada en la emergencia de escenarios urbanos y rurales que no solo se contraponen, sino que también proponen cada uno su estado afirmativo y el cómo asumir y comprender la realidad; un ejemplo es el siguiente sueño:

\begin{abstract}
El sueño mío anoche fue que todas la compañeras (...) algunas, no todas, se habían cambiado de empresa, que no querían trabajar allá, y que se habían ido a trabajar con unas mujeres que son vestidas de amarillo y de verde, que andan rosando las praderas y volean machete por todos lados, y que yo pasé por la carretera y las vi al borde de la carretera con machetes y todo listas para trabajar, qué por qué no iban a volver a trabajar en la costura, en la fábrica que trabajamos, y que les pregunté qué pasaba y que no iban a volver a trabajar allá, que se iban a pasar a trabajar en otra cosa, que no era cosiendo sino voleando machete (...). (Joven G, comunicación personal, 8 de agosto de 2015)
\end{abstract}

Para finalizar, es importante precisar que las consideraciones expuestas sobre la relevancia de natúram en la constitución lógica de los sueños, y el análisis derivado de esta en relación a los jóvenes excombatientes, no pretenden concluir que estas correspondan a un orden lógico privilegiado ni de mayor complejidad o sofisticación que las lógicas modernas y las dinámicas 
urbanas; por el contrario, se considera que esta son fundamentales dentro de las apuestas políticas, sociales y productivas que se desarrollan en relación a la desvinculación. Sin embargo, estas requieren de procesos que no centren sus esfuerzos en asuntos de orden temático y de cumplimiento sino que contemplen los elementos constitutivos y lógicos que soportan las posibilidades, los recursos y los alcances de las diferentes incitativas.

\section{Conclusiones}

\section{Consideraciones finales sobre la conciencia en los procesos de los jóvenes excombatientes}

El proceso de comprensión de las experiencias oníricas de los jóvenes excombatientes ha permitido develar la relevancia de los referentes naturales -natúram- en la vida lógica o en la constitución de la conciencia. Al respecto, es importante considerar que este no es un proceso en abstracto. Por el contrario, implica la experiencia misma de la conciencia, es el hilo conductor y el marco de ordenamiento de toda experiencia. Por lo tanto, considerar los elementos característicos de la constitución de la conciencia en la que habitan psicológicamente los jóvenes excombatientes constituye un paso fundamental e inevitable en un auténtico reconocimiento, encuentro y comprensión de sus realidades, sus mundos y sus recursos.

Pese a que este proceso de constitución de la conciencia o vida lógica del alma-como se expone en este documento- permea y posibilita cualquier campo de la experiencia y de la realidad como pueden ser la inserción social, política y productiva, su consideración en el diseño e implementación de los programas para el tránsito de la vida armada a la vida civil para jóvenes excombatientes no es tenida en cuenta. Es decir, los programas son generalmente diseñados e implementados bajo lógicas que desconocen, subvaloran y desperdician las condiciones y el potencial de los modos de conciencia construidos y habitados por la población excombatiente. No es accidental que la mayoría de los programas sean pensados, implementados y desarrollados bajo lógicas urbanas de eficiencia y productividad moderna. En la actualidad, el mayor número de jóvenes excombatientes vinculados a la ARN (con excepción de las desmovilizaciones y concentraciones derivadas del acuerdo de paz con las FARC) se encuentran concentrados y desarrollando sus procesos de reincorporación en los grandes centros urbanos del país.

El desconocimiento de la relevancia del proceso del alma en los programas de incorporación social, política y productiva de los jóvenes excombatientes a la vida civil puede entenderse como una actuación inconsciente (entendido en esta perspectiva psico-lógica como lo no pensado o reflexionado) por parte de los profesionales, las instituciones y los grupos sociales implicados en estos procesos. Una actuación que, a su vez, deriva en la imposición de nuevos modos de conciencia que se constituyen sin previa consideración en preceptos rectores de los procesos psicosociales, políticos, productivos y legales. 
Al mismo tiempo, esta tensión entre modos de ser y estar en el mundo deriva en lo que en el proceso de investigación se denominó conciencia y tensión entre las lógicas natúram y contranáturam, conflicto expreso en las experiencias oníricas de los jóvenes y que por su extensión será expuesto en otro documento posterior, pero que por ahora podría simplificarse en el hecho de que en la base de los procesos y dificultades de adaptación laboral, urbana, social y cultural que viven los excombatientes se encuentra una tensión psíquica incomprendida y desatendida.

Los jóvenes excombatientes se encuentran en medio de una sociedad que ha instaurado en su consciencia colectiva la necesidad del eficientismo, el acceso a la educación formal, el acceso a las fuerzas productivas como los caminos idóneos para la reinserción social y productiva, reduciendo la complejidad de la situación y descuidando las necesidad tanto de las poblaciones implicadas como la profundidad de los mismos procesos sociales requeridos para la construcción de escenarios sociales posconflicto armado.

Finalmente, resulta indispensable hacer un llamado a los procesos de acompañamiento psicológico y psicosocial en términos de la responsabilidad que les compete al momento de incorporar en sus comprensiones y pragmáticas de la población excombatiente los mundos psicológicos que están presentes, su valor y posibilidades antes que las conciencias ideales planteadas y establecidas en las lógicas e ideales de los programas de reintegración. Al respecto, recordar que la comprensión psico-lógica constituye una forma de ser en el mundo, representa de ese modo una pragmática psico-lógica en el hacer psico-lógico con individuos, grupos sociales, comunidades y en ámbitos tan diversos como la salud mental, los procesos sociales, la política o la construcción de paz.

\section{Referencias}

Aguirre, N. (2010). Jóvenes excombatientes intentan imaginar sus sobrecogedoras experiencias (Tesis de maestría). Pontificia Universidad Javeriana, Bogotá, Colombia.

Bernal, C. (Productor) y González, D. (Director). (2006). Mi última marcha. [Cinta documental]. Colombia: Universidad de Manizales.

Cifuentes, M. R. (2012). Constitución discursiva de la identidad: el cuerpo testimonio del guerrero (Tesis de doctorado). Universidad del Valle, Cali, Colombia.

Garagalza, L. (1990). La interpretación de los símbolos. Barcelona, España: Anthropos.

Giegerich, W. (1998). Prefacio a “La vida lógica del alma. Hacia una noción rigurosa de la psicología”. Recuperado de http:/ / alebica.blogspot.com.co/2012/02/prefacio.html 
Natúram y alma en la guerra: el proceso de constitución de la conciencia de un grupo de jóvenes excombatientes en Colombia

Giegerich, W. (2004). El final del significado y el nacimiento del hombre: un ensayo acerca del estadio alcanzado en la historia de la consciencia y un análisis del proyecto psicológico de C.G. Jung. Recuperado de http://alebica.blogspot.com.co/2009/08/el-final-del-significado-yel_5053.html

Giegerich, W. (2005). El presente como dimensión del Alma. Recuperado de http: / / eskenazi.net/ giegerpresen.html

Giegerich,W. (2006). El sacrificio de Isaac y la línea divisoria de la historia. Observaciones preliminares y metodológicas en torno al tema de las matanzas rituales. Recuperado de http://alebica. blogspot.com.co/2012/05/el-sacrificio-de-isaac.html

Giegerich, W. (2008). Matanzas. Recuperado de http://alebica.blogspot.com.co/2015/05/ matanzas.html

Giegerich, W. (2012). ¿Qué es el Alma? Recuperado de http://alebica.blogspot.com. es/2012/04/que-es-el-alma.html.

Guthrie, W. K. C. (1984). Historia de la filosofía griega. Madrid, España: Editorial Gredos.

Jaramillo, F. (1986). Hegel, una filosofía de lo real. Universitas Philosophica, 7, 45-62.

Jung, C. G. (1995). Acercamiento al inconsciente. El hombre y sus símbolos. Barcelona, España: Paidós.

Lugo, N.V. (2014). Guerreros desarmados. Narrativas con jóvenes excombatientes de Colombia (Tesis de doctorado). Tilburg University, Tilburgo, Países Bajos.

Springer, N. (2012). Como corderos entre lobos: del uso y reclutamiento de niñas, niños y adolescentes en el marco del conflicto armado y la criminalidad en Colombia. Bogotá, Colombia: Springer Consulting SAS. 